\begin{tabular}{ccc}
\hline DE & DE GRUYTER & HUNGARIAN JOURNAL OF \\
\hline & INDUSTRY AND CHEMISTRY & Vol. pp.45(1) pp. $5-8$ (2017) \\
hjic.mk.uni-pannon.hu \\
Dol: $10.1515 /$ hic-2017-0002
\end{tabular}

\title{
SEPARATION OF GASES BY MEMBRANES: THE EFFECTS OF POLLUTANTS ON THE STABILITY OF MEMBRANES
}

\author{
NÁNDOR NEMESTÓTHY* \\ Research Institute of Bioengineering, Membrane Technology and Energetics, University of \\ Pannonia, Egyetem u. 10, Veszprém, H-8200, HUNGARY
}

\begin{abstract}
The long-term stability of membranes is determined mainly by their sensitivity to pollutants. Their stability was tested using a novel, multichannel measuring system, which is based on pressure differences. This measuring system is suitable to determine the changes in permeability of polymer membranes. The damaging effects of $\mathrm{H}_{2} \mathrm{~S}$, BTX and n-dodecane were investigated in terms of polyimide gas separation membranes using nitrogen gas.
\end{abstract}

Keywords: multichannel test equipment, pressure difference, hydrogen sulphide, BTX

\section{Introduction}

Previously, it was thought that the stability of membranes is determined by the mechanical stress (shear) and the natural aging of polymers. Recently, however, it has been confirmed that their stability is limited mainly by the sensitivity of membranes to certain pollutants. These aggressive compounds, pollutants, e.g. chlorine, hydrogen sulphide, hydrocarbons, etc., may damage the structure of the polymer, thus its physical and chemical properties change, and consequently the permselectivity of the membrane changes, as well.

It is known that polymeric reverse osmosis membranes are sensitive to strong oxidising agents, especially chlorine compounds [1], therefore, intensive research has been conducted to avoid or at least reduce any damage [2-3]. Similar levels of membrane degradation are observed in proton-exchange membrane (PEM) fuel cells and batteries containing membranes, where oxidising compounds are in contact with the membranes, as well [4-5].

The stability of polymeric gas separation membranes has hardly been investigated. The long-term effects of $\mathrm{H}_{2} \mathrm{~S}$ on inorganic membranes has been studied by Australian researchers at low concentrations (50 ppm) [6]. However, $\mathrm{H}_{2} \mathrm{~S}$ may not only cause long-term, but immediate damage, mainly in the form of swelling, which strongly influences the gas transport properties of membranes. Koros and co-workers presented the effects of extremely high $\mathrm{H}_{2} \mathrm{~S}$ concentrations on a polymer membrane (50,000 - 100,000 ppm) [7].

In the field of membrane technology, sensitivity can be measured by a sort of effectiveness unit. The

*Correspondence: nemesn@,almos.uni-pannon.hu product of the concentration and time period yields a value where the effectiveness of the membrane decreases from 95 to 90 and then to $70 \%$ of its original value (e.g. 1000 ppm*hour means that the membrane was exposed to $1000 \mathrm{ppm}$ of pollutant for 1 hour, or 0.1 ppm of pollutant for 10,000 hours during the tests).

According to the literature these types of measurements have yet to be published for gas separation membranes, thus the aim of this work was to design, construct and operate a piece of test equipment that conducts reliable laboratory tests.

For the determination of stability, direct and indirect methods can be used to measure the gas volumes passing through the membranes. Direct methods are usually preferred, and - if the composition of the gas is known - are more exact than indirect ones. However, when the gas composition varies and small amounts of gases need to be measured, indirect methods are often more suitable. In this work an indirect method based on a pressure differential technique was chosen, where the pressure of a closed vessel is measured and the varying pressure yields information about the volume of the gas passing through the membrane.

During the investigation the effects of pollutants on the permeability of nitrogen was to be studied. The following pollutants were used:

- compounds containing sulphur at associated gas

- BTX mixture (benzene, toluene, xylene)

- heavy hydrocarbons

In this research the aim was to determine quantitatively the effects of pollutants on the membranes to define the tolerance range of particular membranes. 


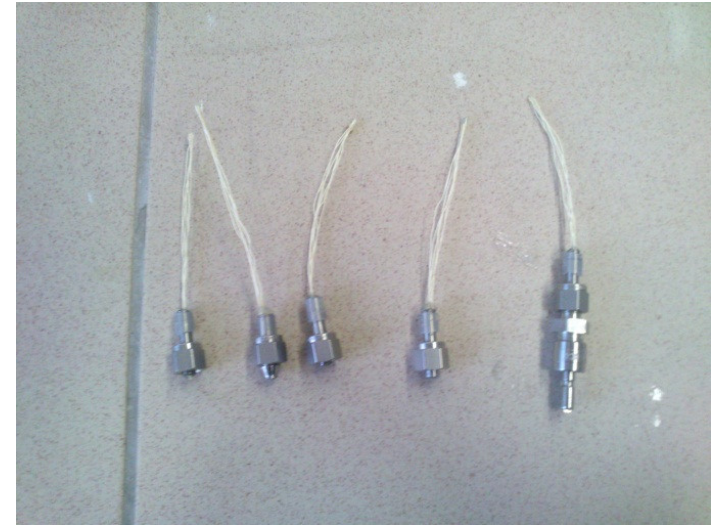

Figure 1. The small modules constructed for the tests

\section{Experimental}

For this series of measurements, polyimide gas separation membranes (synthesised by UBE) were used. They were taken from a hollow fibre module and can accurately model the properties of industrial gas separation membranes. From the hollow fibres small modules containing 6 capillaries were constructed (Fig. 1) and their ends were closed, thus their tests were carried out in a "sack" configuration.

In the design of the test system it was important that several parallel measurements should be conducted and the measuring channels combined with each other. The scheme of a measuring channel can be seen in Fig. 2

The gas was introduced into the measuring system through valve $\mathrm{V} 1$ (which can be adjusted by valve V2 if necessary). Before measurements were taken the pressure of the vessel was checked by pressure transducer PT1. To start the test the pressure was adjusted by regulating valve PV1, which was checked by pressure transducer PT2. Then the membrane was installed into the thermostatic system in a way that ensured its mobility was not restricted, thus the permeation of gas could not influence the flux.

A photograph of the measuring system is shown in Fig.3. For the permeability measurements nitrogen gas from a cylinder was used (99.5\%; Messer Hungarogáz Kft., Hungary).

The permeability of the membrane was determined from the pressure of the vessel and the transmembrane pressure measured on-line during the experiments. In the experiments, $\mathrm{H}_{2} \mathrm{~S}$, methyl mercaptan and ammonia (compounds containing $\mathrm{S}$ or $\mathrm{N}$ ), oleic acid, ethyl

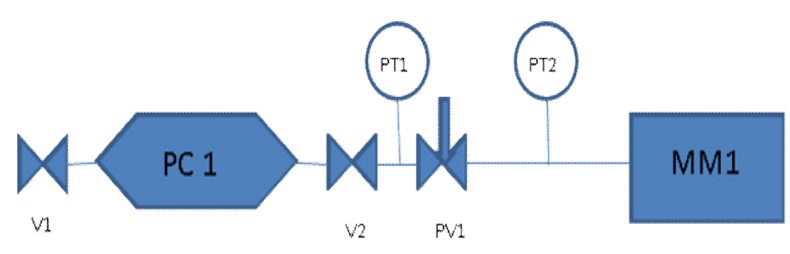

Figure 2. The scheme of the test system

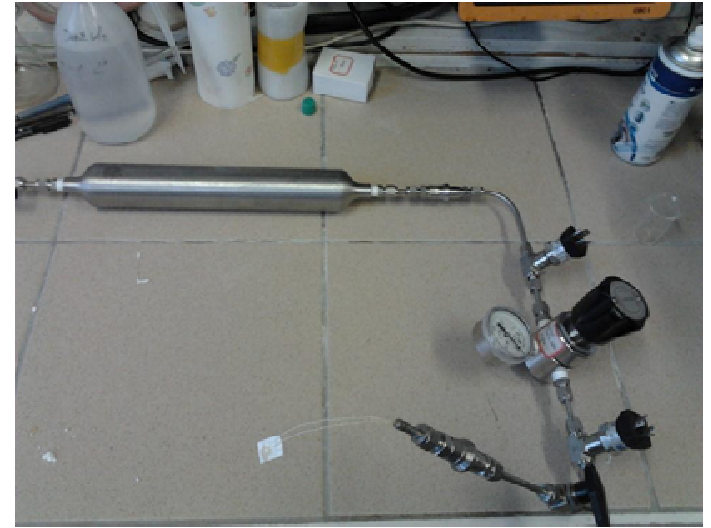

Figure 3. The test system

alcohol, moreover, a benzene-toluene-xylene mixture (BTX) and n-dodecane (as a heavier hydrocarbon) were used as pollutants.

For the stability experiments the small membrane modules were put in a closed vessel (Fig.4) where the headspace was saturated with the given pollutant. The vessels were placed in a thermostatic incubator at $27{ }^{\circ} \mathrm{C}$ usually for between 1 and 7 days.

Certain materials (e.g. BTX) damaged the epoxy resin glue used to adhere the fibres of the membranes, therefore, these experiments were repeated using polyether-sulfone glue instead.

\section{Results}

The nitrogen permeability of the membranes was determined before and after the incubations.

In the preliminary experiments, the ammonia solution and methyl mercaptan severely damaged the surface of the membranes, thus no flux could be measured. Oleic acid and ethyl alcohol hardly influenced the flux, while BTX, $\mathrm{H}_{2} \mathrm{~S}$ and n-dodecane changed the permeability of nitrogen considerably.

For further investigation of the pollutants an experimental design was constructed, using appropriate

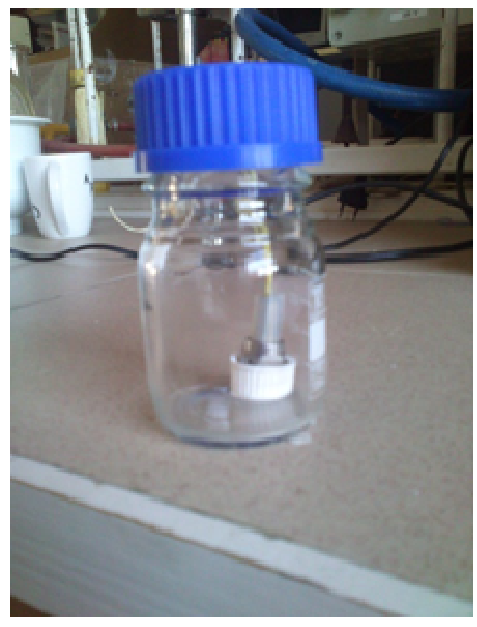

Figure 4: The membranes in the closed vessel

Hungarian Journal of Industry and Chemistry 
Table 1. The parameters of the experimental design

\begin{tabular}{|l|l|l|l|l|l|l|}
\hline $\begin{array}{l}\text { pollu- } \\
\text { tant }\end{array}$ & $\begin{array}{l}\mathrm{c}_{\min } \\
\mathrm{ppm}\end{array}$ & $\begin{array}{l}\mathrm{c}_{\mathrm{av}} \\
\mathrm{ppm}\end{array}$ & $\begin{array}{l}\mathrm{c}_{\max } \\
\mathrm{ppm}\end{array}$ & $\begin{array}{l}\mathrm{t}_{\min } \\
\mathrm{d}\end{array}$ & $\begin{array}{l}\mathrm{t}_{\mathrm{av}} \\
\mathrm{d}\end{array}$ & $\begin{array}{l}\mathrm{t}_{\max } \\
\mathrm{d}\end{array}$ \\
\hline $\mathrm{H}_{2} \mathrm{~S}$ & 100,000 & 300,000 & 500,000 & 1 & 3.5 & 7 \\
\hline $\begin{array}{l}\mathrm{BTX} \\
\text { mixt. }\end{array}$ & 1,000 & 750 & 500 & 1 & 3.5 & 7 \\
\hline $\begin{array}{l}\text { dode- } \\
\text { cane }\end{array}$ & 1,000 & 5,500 & 10,000 & 1 & 3.5 & 7 \\
\hline
\end{tabular}

statistical methods. The parameters selected were the concentrations of the pollutants (minimum, maximum and average) and the incubation time (minimum, maximum and average). The Statistica 8 computer program was applied to the design presented in Table 1 .

Firstly the effect of $\mathrm{H}_{2} \mathrm{~S}$ on the nitrogen permeability of the membranes was measured. The experimental results are presented in Fig.5.

It can be seen that the permeability of nitrogen increased even when the concentrations of pollutants were low and rose by using higher concentrations and longer periods of exposure.

From the $\mathrm{H}_{2} \mathrm{~S}$ concentration and the incubation time it was possible to calculate a special parameter of exposure with the unit of $\mathrm{ppm}^{*} \mathrm{~h}$. Permeability was presented as a function of this parameter (Fig.6), where an almost linear relationship was observed.

The results suggest that the process can be described as a first-order reaction, which means that no safe limit can be determined where $\mathrm{H}_{2} \mathrm{~S}$ is regarded as harmless, on the contrary, it should be considered at all times.

The effect of the BTX mixture was studied using a similar methodology. The results are summarized in Fig.7. This figure shows that the permeability of nitrogen increased at low concentrations of the BTX mixture. At higher concentrations and over longer periods of time, no further significant changes were observed.

The exposure parameter was also calculated in the unit of $\mathrm{ppm}^{*} \mathrm{~h}$ and permeability was presented as its function (Fig.8). The diagram can be described as a saturation-type curve.
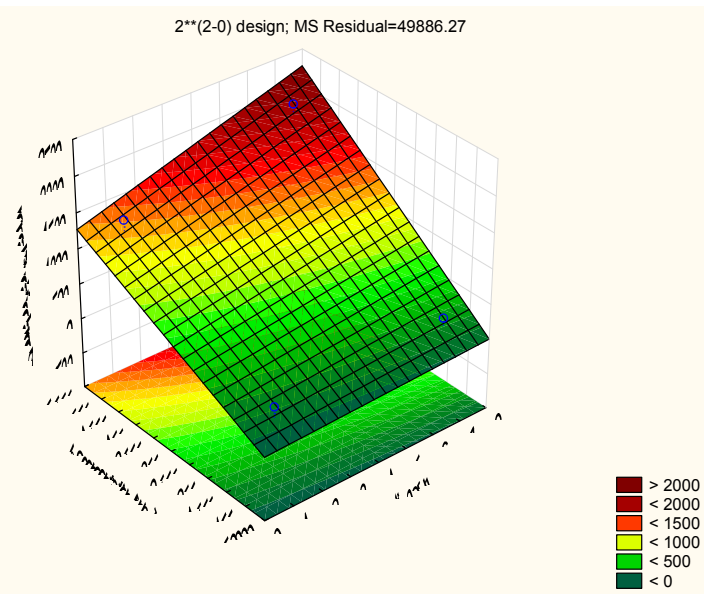

Figure 5. The effect of $\mathrm{H}_{2} \mathrm{~S}$ on the nitrogen permeability

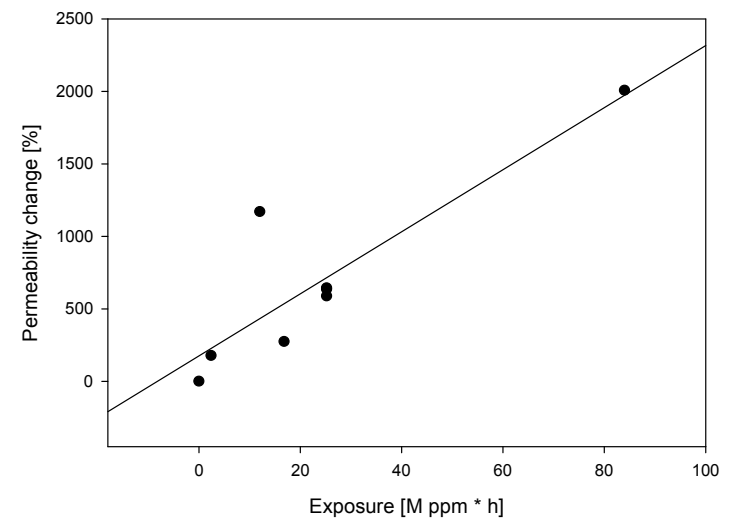

Figure 6. Permeability changes against exposure to $\mathrm{H}_{2} \mathrm{~S}$

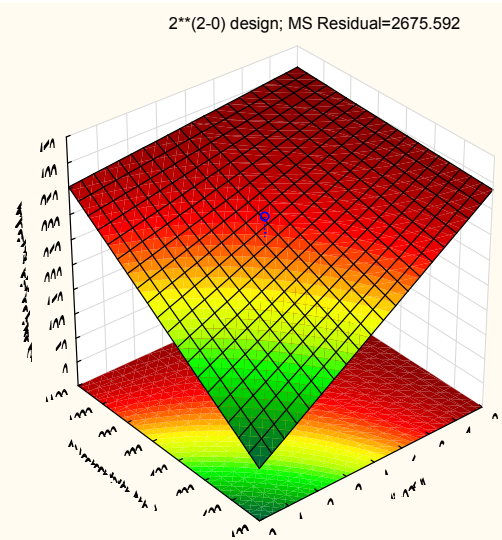

Figure 7: The effect of the BTX mixture

In the last series of experiments, the effect of exposure to $\mathrm{n}$-dodecane was investigated experimentally. The results are presented in Fig.9.

n-dodecane caused - unlike $\mathrm{H}_{2} \mathrm{~S}$ and BTX - a reduction in the permeability of nitrogen even at low concentrations. The flux fell to zero at higher concentrations and over longer incubation periods.

Permeability was investigated as a function of exposure (Fig.10). The process can be described as a first-order reaction, thus the effect of heavier hydrocarbons, e.g. n-dodecane, should always be considered.

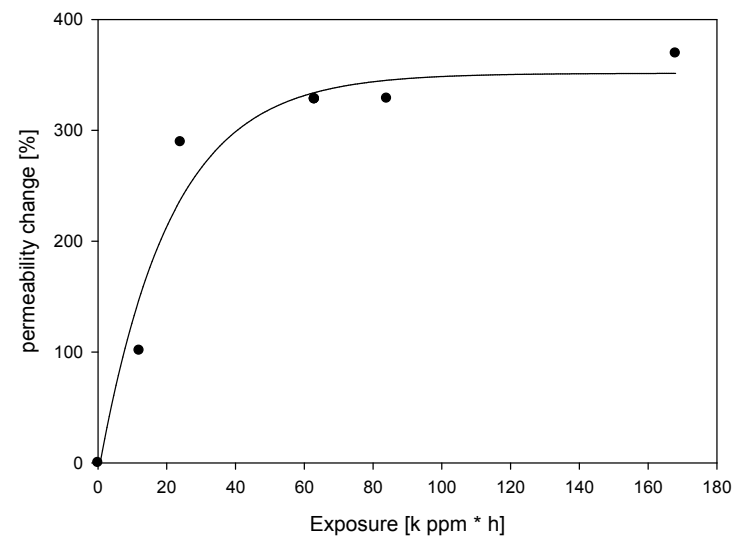

Figure 8: Permeability changes against BTX exposure 


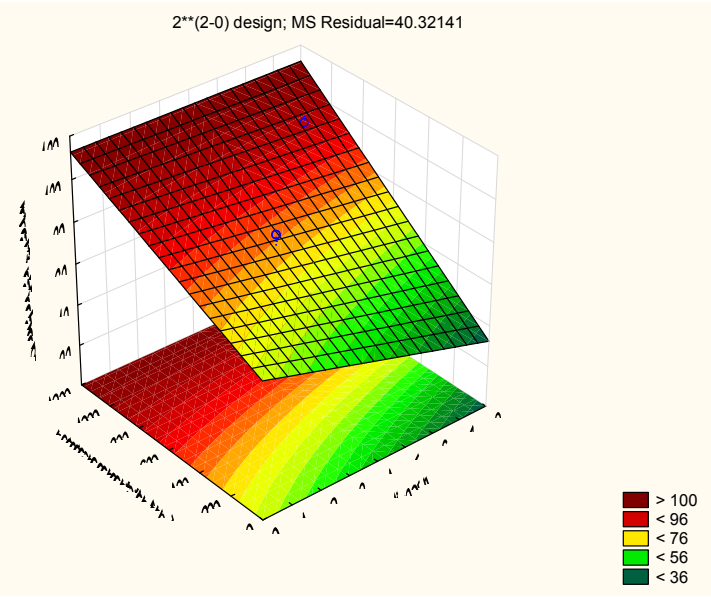

Figure 9: The effect of n-dodecane

\section{Conclusion}

The long-term stability of polyimide gas separation membranes was tested against various pollutants: $\mathrm{H}_{2} \mathrm{~S}$, a BTX mixture and n-dodecane. These compounds significantly affected the nitrogen permeability of the membranes which were described by using a special parameter of exposure. It was found that $\mathrm{H}_{2} \mathrm{~S}$ and the BTX mixture increased the permeability, while ndodecane reduced the permeability of the membranes. Further investigations are planned to investigate the effect of other pollutants, moreover, to determine the permeability of additional gases, e.g. carbon dioxide, methane, etc.

\section{Acknowledgement}

We acknowledge the financial support of Széchenyi 2020 under the EFOP-3.6.1-16-2016-00015 project. This research was supported by the János Bolyai Research Scholarship of the Hungarian Academy of Sciences.

\section{REFERENCES}

[1] Glater, J.; Hong, S.K.; Elimelech, M.: The search for a chlorine-resistant reverse osmosis membrane, Desalination, 1994 95(3), 325-345 DOI: 10.1016/0011-9164(94)00068-9

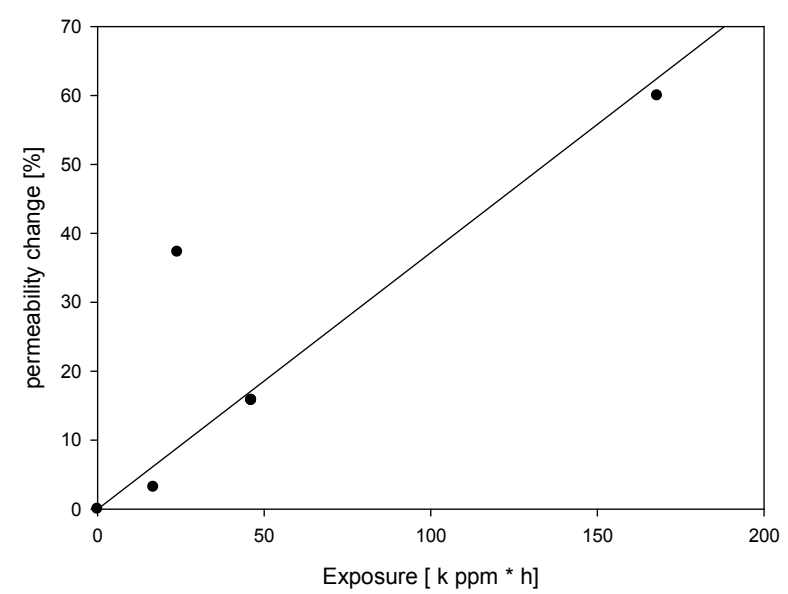

Figure 10. Change in permeability against exposure to n-dodecane

[2] Zhang, Y.; Zhao, C.; Yan, H.; Pan, G.; Guo, M.; $\mathrm{Na}$, H.; Liu, Y.: Highly chlorine-resistant multilayer reverse osmosis membranes based on sulfonated poly(arylene ether sulfone) and poly(vinyl alcohol), Desalination, 2014 336, 58-63 DOI: 10.1016/j.desal.2013.12.034

[3] Gohil, J.M.; Suresh, A.K.: Chlorine attack on reverse osmosis membranes: Mechanisms and mitigation strategies, J. Membr. Sci., 2017 541, 108-126 DOI: 10.1016/j.memsci.2017.06.092

[4] Huang, X.; Pu, Y.; Zhou, Y.; Zhang, Y.; Zhang, H.: In-situ and ex-situ degradation of sulfonated polyimide membrane for vanadium redox flow battery application, J. Membr. Sci., 2017 526, 281292 DOI: 10.1016/j.memsci.2016.09.053

[5] Lapicque, F.; Belhadj, M.; Bonnet, C.; Pauchet, J.; Thomas, Y.: A critical review on gas diffusion micro and macroporous layers degradations for improved membrane fuel cell durability, J. Power Sources, $2016 \quad 336, \quad 40-53$ DOI: 10.1016/j.jpowsour.2016.10.037

[6] Uhlmann, D.; Smart, S.; Diniz da Costa, J.C.: $\mathrm{H}_{2} \mathrm{~S}$ stability and separation performance of cobalt oxide silica membranes, J. Membr. Sci., 2011 380(1), 48-54 DOI: 1016/j.memsci.2011.06.025

[7] Kraftschik, B.; Koros, W.J.; Johnson, J.R.; Karvan, O.: Dense film polyimide membranes for aggressive sour gas feed separations, J. Membr. Sci., $2013 \quad 428, \quad 608-619$ DOI: 10.1016/j.memsci.2012.10.025 